\title{
Outcome Following Surgical Correction of Abomasal Displacement in Lactating Dairy Cattle: A Retrospective Study of 127 Cases (1999-2010)
}

\author{
Rebecca L. Pentecost ${ }^{1}$, Andrew J. Niehaus ${ }^{1^{*}}$, David E. Anderson ${ }^{2}$, Matt D. Miesner ${ }^{3}$ and D. Michael Rings ${ }^{1}$ \\ ${ }^{1}$ Department of Veterinary Clinical Sciences, College of Veterinary Medicine, The Ohio State University, Columbus, \\ $\mathrm{OH}, 43210$, USA \\ ${ }^{2}$ Department of Large Animal Clinical Sciences, College of Veterinary Medicine, University of Tennessee, Knoxville, \\ TN, USA \\ ${ }^{3}$ Department of Clinical Sciences, College of Veterinary Medicine, Kansas State University, Manhattan, KS, USA
}

${ }^{*}$ Corresponding author: Andrew J. Niehaus, Department of Veterinary Clinical Sciences, College of Veterinary Medicine, The Ohio State University, Columbus, OH, 43210, USA, Tel: (614) 292-6661, E-mail: niehaus.25@osu.edu

Citation: Rebecca L. Pentecost, Andrew J. Niehaus, David E. Anderson, Matt D. Miesner, D. Michael Rings (2014) Outcome Following Surgical Correction of Abomasal Displacement in Lactating Dairy Cattle: A Retrospective Study Of 127 Cases (1999-2010). J Vet Sci Anim Husb 2(1): 102. doi: 10.157444/2348-9790.1.402

Received Date: December 12, 2013 Accepted Date: February 20, 2014 Published Date: February 24, 2014

\begin{abstract}
The objectives of this retrospective study were 1. To determine the effect of three surgical techniques (right flank omentopexy, right flank omentoabomasopexy, and left flank abomasopexy), and 2. To determine the effect of concurrent disease on return to normal milk production. Return to normal milk production occurred in $86.3 \%$ of cows diagnosed with LDA. Results suggested that cattle diagnosed with LDA corrected via right flank omentopexy or left flank abomasopexy were significantly more likely to return to normal milk production as compared to those corrected via right flank omentoabomasopexy $(\mathrm{p}<0.02)$. No significant difference in return to normal milk production was noted between surgical techniques for correction of RDA $(\mathrm{p}=1.000)$ and right abomasal volvulus $(\mathrm{p}=0.596)$. Concurrent disease diagnoses did not affect return to milk production. Reported complications were infrequent $(\mathrm{n}=11)$.

List of abbreviations: LDA- Left displaced abomasum; RDA- Right displaced abomasum; RAV- Right abomasal volvulus; RAOV- Right abomasal-omasal volvulus; RFO- Right flank omentopexy; RFOA- Right flank omentoabomasopexy; LFA- Left flank abomasopexy; DA - Displaced Abomasum
\end{abstract}

\section{Introduction}

Methods described for correction of abomasal displacement include rolling, rolling and tacking / blind toggle pin placement, and various surgical methods [1-11]. Reports of nonsurgical correction techniques describe success rates similar to surgical techniques but document complications inherent to blind techniques [10,12]. Surgical correction of an abomasal displacement allows for definitive diagnosis, more reliable replacement and immobilization of the abomasum in an appropriate anatomic position, potential evaluation of other abdominal organs relevant to the post-parturient dairy cow, and more accurate prognostication due to palpable and visual inspection of the abomasum and other abdominal structures. Both minimally invasive and open surgical techniques have been described and validated for correction of the displaced abomasum [1,3,4,7-9].

Decreased milk production is noted in cows suffering from DA's. This decrease in milk production is largely attributed to the displacement rather than the surgical correction. A few reports compared the potential effect of various open surgical techniques on milk production $[4,13]$. One report showed a trend towards higher milk production with a right paramedian abomasopexy technique as compared to the right flank omentopexy technique although statistical significance was not attained and there was no statistical difference in long term milk production [4]. We hypothesized that there would be no difference in outcome among three commonly used open laparotomy techniques: Right Flank Omentopexy (RFO), Right Flank Omentoabomasopexy (RFOA), and Left Flank Abomasopexy (LFA) with regard to return to normal milk production in lactating dairy cattle affected with displacement of the abomasum.

Cows suffering from a displaced abomasum commonly presents to the veterinary clinic with other complicating conditions. Most notably in our clinic are fresh cow diseases such as metritis, mastitis, and ketosis. The influence that these concurrent diseases have on the recovery of cows following correction of abomasal displacements is not well understood. Hence another objective of this study was to determine if cattle affected with concurrent diseases had a poorer outcome than cows suffering with an uncompleted 
abomasal displacement.

The objectives of this retrospective study were 1 . to determine the effect of surgical technique, and 2. to determine the effect of concurrent diseases on return to normal milk production.

\section{Mainbody}

Lactating dairy cattle presenting to the Ohio State University Veterinary Medical Center for LDA, RDA, RAV (Right Abomasal Volvulus), or RAOV (Right Abomasal-Omasal Volvulus) over an eleven year period from April 1999 to January 2010 and for which follow up data could be obtained were studied. Patient and owner information was recorded along with historical information including the date of calving or approximate days in milk (DIM), if known. The type of abomasal displacement (LDA, RDA, $\mathrm{RAV}, \mathrm{RAOV}$ ) was recorded. Concurrent problems such as ketosis (assessed by the presence of urine ketones $\geq 15 \mathrm{mg} / \mathrm{dl}$ ), $\mathrm{metritis}$ (as assessed by the presence feted uterine discharge in post partum cows), or mastitis (assessed by abnormal appearing milk on black plate examination, hot and swollen quarter(s), quarter(s) painful on palpation, or a positive California Mastitis Test) were recorded. The method of surgical correction (RFO, RFOA, or LFA), surgeon, date of surgery, and date of hospital discharge (if applicable) was also recorded. The reason for selecting the method of surgical correction was recorded if known.

A generalized description of surgical technique follows: RFO was performed similar to the technique described by Turner and McIlwraith [14] using a right paralumbar approach. After abdominal exploration, excess gas was released from the displaced abomasum using a needle attached to suction tubing. The abomasum was repositioned to the right cranial abdomen and the greater omentum was retracted caudally and dorsally until the pyloric antrum of the abomasum was visualized at the lower edge of the abdominal incision. The omentum was incorporated into the first layer of closure with the transversus abdominis using \#3 chromic gut suture in a simple continuous pattern. Most surgeons preplaced additional mattress sutures cranial and caudal to the primary incision prior to the continuous line closure. The second muscle layer included the internal and external abdominal oblique muscles and was closed using \#3 chromic gut in a simple continuous pattern. The skin was closed using \#3 Braunamid in a Ford-interlocking pattern.

RFOA was performed through a right paralumbar incision with abdominal exploration and abomasal replacement in a similar fashion to the RFO. A small stab incision was created cranial and ventral to the primary incision. Suture material was placed through the stab incision and an abomasopexy placed in the pyloric antrum using either \#3 chromic gut or \#3 Braunamid depending on surgeon preference. An omentopexy was performed during abdominal closure as previously described.

LFA was performed using a left paralumbar incision similar to the technique described by Turner and McIlwraith [14]. Abdominal exploration was limited due to the blocking effect of the rumen from the left approach. The abomasum was identified and \#3 Braunamid suture was placed in the greater curvature of the abomasum with long strands at either end of the pexy site. The free ends of the suture were passed by the surgeon under the rumen along the left body wall exiting the abdomen right of midline and several inches caudal to the xiphoid. The abomasum was repositioned to its normal location while an assistant tightened the sutures prior to knot tying. A stent was placed to decrease tension on the underlying skin. Sutures were removed 14 days post operatively.

Follow-up information was collected via client questionnaires and telephone interviews. A standardized questionnaire gathered information on milk production and surgical complications following surgery. Clients were asked to report the cow's milk production prior to displacement, immediately following surgical correction, and during subsequent lactations. Owners were asked to provide a subjective assessment of whether they felt the animal returned to "normal milk production" following the surgical correction if specific production data were not available. Complications associated with surgery as well as recurrence of abomasal displacement were also recorded. Specifically, the clients were questioned if the cow developed incision infections, dehiscence, peritonitis, or gastrointestinal disturbances such as inappetance, bloat, diarrhea, or another DA. Clients were questioned as to whether the cows ever suffered post operatively from other diseases such as mastitis, metritis, ketosis, or a dystocia. Cows were said to have an LDA if the abomasum was found left of midline trapped between the rumen and the left body wall. Cows were said to have a RAV if (1) the abomasum was located on the right side of the abdominal cavity in the cranial abdominal quadrant; (2) the abomasum was distended causing medial displacement of the liver such that the diaphragmatic surface of the liver no longer contacted the right abdominal wall; and (3) a firm twist was palpated at the omasal-abomasal junction [1]. Cows were said to have a RDA if (1) the abomasum was located on the right side of the abdominal cavity in the cranial abdominal quadrant; (2) the abomasum was distended but not causing the degree of liver displacement as noted for the RAV; and (3) a firm twist was not palpated at the omasal-abomasal junction. Cows were said to have a RAOV if (1) the abomasum was located on the right side of the abdominal cavity in the cranial abdominal quadrant; (2) the abomasum was distended causing medial displacement of the liver such that the diaphragmatic surface of the liver no longer contacted the right abdominal wall; and (3) a firm twist was palpated at the reticuloomasal junction. RAOV and RAV were grouped together for statistical analysis.

Fisher's exact test was performed to assess the significance of return to normal milk production for the three surgical procedures as well as for primary and secondary diagnoses due to small sample size in some categories. GraphPad Prism was used for statistical 
analysis. Significance for all comparisons was set at $\mathrm{P}<0.05$.

\section{Results}

A review of medical records over an 11 year period from 1999 through 2010 revealed 678 cases of abomasal displacement that were corrected surgically at the OSU Veterinary Medical Center using RFO, RFOA, or an LFA. Breeds of cattle included Holstein $(n=562)$, Jersey $(n=88)$, Guernsey $(n=14)$, Ayrshire $(n=7)$, Brown Swiss $(n=6)$, and Milking Shorthorn $(n=1)$. The median age of cattle undergoing surgery was 4.2 years (mean: $4.4 \pm 1.7$ years; range 1.7-16.5 years). The median days in milk was 14 days (mean $=43.2 \pm 87.2$ days; range: $1-735$ days) at the time of surgery. The majority of cows were diagnosed with LDA ( $n=532)$, followed by $\operatorname{RAV}(\mathrm{n}=106)$ and RDA $(\mathrm{n}=40)$.

Out of 678 cows having surgical correction of abomasal displacement, 664 (98\%) were discharged from the hospital and returned to the dairy farm. Duration of hospitalization was recorded for these 664 cows with the majority receiving outpatient treatment $(\mathrm{n}=387)$. Hospitalization lasting 1-7 days was recorded for 243 cases, between 8-14 days for 26 cases, and greater than 14 days for 8 cases. Post-operative complications noted prior to discharge were infrequent $(n=11)$. Complications included incisional infection or seroma $(n=6)$, peritonitis $(n=1)$, rumen bloat $(n=1)$ and redisplacement $(n=3)$. Incisional infections resolved at the farm, the cow with bloat resolved prior to discharge, the cow with peritonitis died in the hospital, and all three cows with recurrent abomasal displacements were discharged prior to redisplacement and did not have the displacement corrected. All three of the cows that had a recurrent displacement of the abomasum were originally diagnosed with an LDA that was corrected with a RFO.

Long-term follow-up information was available for 127 patients (Table 1) and included 100 obtained for cows with LDA. Return to normal milk production occurred in $86.3 \%$ of cows diagnosed with LDA. Cows diagnosed with LDA corrected by RFO or LFA were significantly more likely to return to normal milk production as compared to RFOA (Fisher's Exact Test; $\mathrm{p}=0.020$ ). Follow-up was obtained for 18 cows diagnosed with RAV. Return to normal milk production occurred in $72.2 \%$ ( $n=13$ ) of these cows with no significant difference between the RFO and RFOA techniques (Fisher's exact test; $\mathrm{p}=1.000$ ). For cows diagnosed with RDA, followup was available for 9 cows. Return to normal milk production was observed in $77.8 \%(n=7)$ of these cows with no significant difference between the RFO and RFOA techniques (Fisher's exact test; $\mathrm{p}=0.596$ ).

\begin{tabular}{|c|c|c|c|c|c|c|c|c|c|}
\hline & \multicolumn{3}{|l|}{$\mathrm{LDA}^{\mathrm{a}}$} & \multicolumn{3}{|l|}{$\mathrm{RAV}^{\mathrm{b}}$} & \multicolumn{3}{|l|}{$\mathrm{RDA}^{\mathrm{c}}$} \\
\hline & \multicolumn{3}{|c|}{ Return to Normal Milk Production? } & \multicolumn{3}{|c|}{ Return to Normal Milk Production? } & \multicolumn{3}{|c|}{ Return to Normal Milk Production? } \\
\hline & Yes & No & Total & Yes & No & Total & Yes & No & Total \\
\hline${ }^{\mathrm{d}} \mathrm{RFO}$ & $\begin{array}{l}71 \\
(91.0 \%)\end{array}$ & $\begin{array}{l}7 \\
(9.0 \%)\end{array}$ & 78 & $\begin{array}{l}7 \\
(63.6 \%)\end{array}$ & $\begin{array}{l}4 \\
(36.4 \%)\end{array}$ & 11 & $\begin{array}{l}4 \\
(80.0 \%)\end{array}$ & $\begin{array}{l}1 \\
(20.0 \%)\end{array}$ & 5 \\
\hline${ }^{\mathrm{e}} \mathrm{RFOA}$ & $\begin{array}{l}10 \\
(66.7 \%)\end{array}$ & $\begin{array}{l}5 \\
(33.3 \%)\end{array}$ & 15 & $\begin{array}{l}6 \\
(85.7 \%)\end{array}$ & $\begin{array}{l}1 \\
(14.3 \%)\end{array}$ & 7 & $\begin{array}{l}3 \\
(75.0 \%)\end{array}$ & $\begin{array}{l}1 \\
(25.0 \%)\end{array}$ & 4 \\
\hline fLFA & $\begin{array}{l}5 \\
(71.4 \%) \\
\end{array}$ & $\begin{array}{l}2 \\
(28.6 \%)\end{array}$ & 7 & N/A & N/A & & N/A & N/A & \\
\hline Total & $\begin{array}{l}86 \\
(86.0 \%)\end{array}$ & $\begin{array}{l}14 \\
(14.0 \%)\end{array}$ & 100 & $\begin{array}{l}13 \\
(72.2 \%)\end{array}$ & $\begin{array}{l}5 \\
(27.8 \%)\end{array}$ & 18 & $\begin{array}{l}7 \\
(77.8 \%)\end{array}$ & $\begin{array}{l}2 \\
(22.2 \%)\end{array}$ & 9 \\
\hline
\end{tabular}

Table Legend:

${ }^{\text {a }}$ Left displaced abomasum

${ }^{\mathrm{b}}$ Right abomasal volvulus

${ }^{c}$ Right displaced abomasum

d Right flank omentopexy

e Right flank omentoabomasopexy

${ }^{\mathrm{f}}$ Left flank abomasopexy

Table 1: Return to normal milk production grouped according to type of abomasal displacement and surgical correction method.

The impact of primary diagnosis (LDA, RAV, RDA) on return to normal milk production was evaluated using a Fisher's exact test. No significant difference was noted between cows diagnosed with LDA, RAV, or RDA and return to milk production ( $\mathrm{p}=0.235$ ). 54 of the 127 cows with follow up had a secondary disease recorded in the medical record with an overall return to milk production of $85.1 \%(n=46 / 54)$. Cows with a concurrent diagnosis of metritis had a $100 \%(n=5 / 5)$ return to milk production followed by ketosis $(86.2 \% ; n=25 / 29)$, mastitis $(83.3 \% ; n=5 / 6)$, adhesions or peritonitis $(81.8 \% ; n=9 / 11)$, and musculoskeletal lesions $(66.7 \%$; $n=2 / 3)$. There was no significant difference in return to milk production between cows with secondary diseases recorded those without. (Fisher's exact test; $\mathrm{p}=0.661$ ).

\section{Discussion}

Displacement of the abomasum is one of the most common disorders affecting the periparturient dairy cow with an incidence 
reported from less than $1 \%$ up to $15 \%$ with a mean of $1 \%$ up to $5 \%$ [15-18]. Abomasal displacements create significant economic repercussions for producers due to the marked decrease in milk production and increased cost associated with correction or culling [13,19-21]. Numerous predisposing factors and potential etiopathogeneses have been suggested for development of abomasal displacement. Suggested predisposing factors include sex, pregnancy, parity, birth of twins, breed, body size, genotype, season of year, and diet [22-31].

The breed distribution in this study was consistent with our overall hospital admissions for dairy cattle. The average age at the time of abomasal displacement and surgical correction, as well as the median time for days in milk, are consistent with previous reports [30]. Similarly, LDA was the most common displacement to occur [32]. A number of surgical and nonsurgical approaches have been described for correction of abomasal displacement. Nonsurgical techniques are rarely performed at our institution. Surgeons routinely elect open surgical techniques with RFO, RFOA, and LFA comprising the majority of procedures.

Cows diagnosed with an LDA corrected by RFO or LFA were significantly more likely to return to normal milk production than those that were corrected via RFOA. This finding suggests that the increased security provided by an abomasopexy does not correlate to higher milk production postoperatively. It is likely that case selection and surgeon preference for a certain procedure biased our results. Some surgeons routinely add an abomasopexy to the right flank omentopexy in situations that they feel an omentopexy alone has a high likelihood of failure. Examples of intra-operative findings that may influence the decision to perform right flank abomasopexy in addition to omentopexy include excessively thin omentum, friable omentum with tears or avulsion of the omentum, and prior omentopexy.

Although the original number of cases of cattle with abomsal displacements in this retrospective study (678) seems adequate, follow-up was poor due to the 11 year study period over which the surgeries were performed. This prohibited us from being able to stratify the data and take additional parameters into account such as age at surgery, breed, and surgeon effect, because when we did, the number of cases in each of the group was very low. Perhaps if we were able to better correct for these other variables we would have been able to better identify an effect of surgery.

Because of variation among individual cows, different breeds, and different management schemes, we based "normal" milk production on the production of the cow prior to the abomsal displacement. For cattle that displaced too early in their lactation to accurately define their baseline production, their "normal" milk production was based on their production in previous lactations. If no previous milk production data was available for a given cow, "normal" milk production was based on similar cows from the herd of origin.

The number of cases in the RDA group is very low, especially after follow-up was obtained. Hence the statistical power is very low for this dataset. No conclusions can be made from these data.

In this study population, neither primary nor secondary diagnosis had a significant impact on return to normal milk production in contrast to previous reports [33]. We expected to find that cows having ketosis may be at increased risk for having a fatty, friable omentum that might predispose to tearing or stretching of an omentopexy in the early postoperative period. No such association could be identified. Increased numbers of cases with more detailed follow-up may have allowed us to better define the potential role of these sequela within the study population.

\section{Conclusions}

Our data suggests that LDA corrected via RFO or LFA are more likely to return to normal milk production as compared to those whose displacements are corrected via a RFOA. We could not detect a significant difference between RFO and RFOA with regards to return to milk production for cows diagnosed with right sided displacements. Case selection may bias these results and further prospective studies evaluating surgical approach are required. In our study population concurrent disease did not impact the likelihood of returning to normal milk production.

\section{Acknowledgements}

The authors would like to thank all of the veterinarians of The Ohio State University who contributed cases to this retrospective study.

\section{References}

1. Niehaus AJ (2008) Surgery of the abomasum. Veterinary clinics of North America. Food animal practice 24: $349-358$.

2. Ames S 2nd (1968) Repositioning displaced abomasum in the cow. J Am Vet Med Assoc 153: 1470-1471. 
3. Babkine M, Desrochers A, Boure L, Helie P (2006) Ventral laparoscopic abomasopexy on adult cows. The Can Vet J. 47: $343-348$.

4. Fubini SL, Durcharme NG, Erb HN, Sheils RL (1992) A comparison in 101 dairy cows of right paralumbar fossa omentopexy and right paramedian abomasopexy for treatment of left displacement of the abomasum. Can Vet J 33: 318-324.

5. Gertsen KE (1967) Surgical correction of the displaced abomasum. Vet Medicine Small Anim Clin 62: 679-682.

6. Jorritsma R, Westerlaan B, Bierma MP, Frankena K (2008) Milk yield and survival of Holstein-Friesian dairy cattle after laparoscopic correction of left-displaced abomasum. Vet Rec 162: 743-746.

7. Newman, KD, Harvey D, Roy JP (2008) Minimally invasive field abomasopexy techniques for correction and fixation of left displacement of the abomasum in dairy cows. Vet Clin North Am Food Anim Pract 24: 359-382.

8. Roy JP, Harvey D, Belanger AM, Buczinski S (2008) Comparison of 2-step laparoscopy-guided abomasopexy versus omentopexy via right flank laparotomy for the treatment of dairy cows with left displacement of the abomasum in on-farm settings. J Am Vet Med Assoc 232: $1700-1706$.

9. Ruegg PL, Carpenter TE (1989) Decision-tree analysis of treatment alternatives for left displaced abomasum. J Am Vet Med Assoc. 195(4): 464-467.

10. Tithof PK, Rebhun WC (1986) Complications of blind-stitch abomasopexy: 20 cases (1980-1985). J Am Vet Med Assoc 189: 1489-1492.

11. Wittek T, Locher LF, Alkaassem A, Constable PD (2009) Effect of surgical correction of left displaced abomasum by means of omentopexy via right flank laparotomy or two-step laparoscopy-guided abomasopexy on postoperative abomasal emptying rate in lactating dairy cows. J Am Vet Med Assoc 234: 652-657.

12. Sterner KE, Grymer J, Bartlett PC, Miekstyn MJ (2008) Factors influencing the survival of dairy cows after correction of left displaced abomasum. J Am Vet Med Assoc 232: 1521-1529.

13. Fourichon C, Seegers H, Bareille N, Beaudeau F (1999) Effects of disease on milk production in the dairy cow: a review. Prev Vet Med 41: 1-35.

14. Turner AS, McIlwraith CW (1989) Techniques in Large Animal Surgery. Veterinary Surgery 2nd edn, Lippincott Williams \& Wilkins, Philadelphia, USA.

15. Trent AM (1990) Surgery of the bovine abomasum. Vet Clin North Am Food Anim Prac 6: 399-48.

16. Geishauser T, Leslie K, Duffield T (2000) Metabolic aspects in the etiology of displaced abomasum. Vet Clin North Am Food Anim Prac 16: $255-265$.

17. Doll K, Sickinger M, Seeger T (2009) New aspects in the pathogenesis of abomasal displacement. Vet J 181: 90-96.

18. Fetrow J, Eicker S (2003) High production and health - a curious paradox. Bovine Practitioner 37: 128-136.

19. Detilleux JC, Grohn YT, Eicker SW, Quaas RL (1997) Effects of left displaced abomasum on test day milk yields of Holstein cows. J Dairy Sci, 80: $121-126$.

20. Bartlett PC, Kopcha M, Cope PH, Ames NK, Ruegg PL, et al. (1995) Economic comparison of the pyloro-omentopexy vs the roll-and-toggle procedure for treatment of left displacement of the abomasum in dairy cattle. J Am Vet Med Assoc, 206: 1156-1162.

21. Van Winden SC, Jorritsma R, Muller KE, Noordhuizen JP (2003) Feed intake, milk yield, and metabolic parameters prior to left displaced abomasum in dairy cows. J Dairy Sci 86: 1465-1471.

22. Daniel RC (1983) Motility of the rumen and abomasum during hypocalcaemia. Can J Comp Med 47: 276-280.

23. Madison JB, Troutt HF (1988) Effects of hypocalcaemia on abomasal motility. Res Vet Sci 44: 264-266.

24. Turck G, Leonhard-Marek S (2010) Potassium and insulin affect the contractility of abomasal smooth muscle. J Dairy Sci 93: $3561-3568$.

25. Sen I, Ok M, Coskun A (2006) The level of serum ionised calcium, aspartate aminotransferase, insulin, glucose, betahydroxybutyrate concentrations and blood gas parameters in cows with left displacement of abomasum. Pol J Vet Sci 9: 227-232.

26. Itoh N, Koiwa M, Hatsugaya A, Yokota H, Taniyama H, et al. (1998) Comparative analysis of blood chemical values in primary ketosis and abomasal displacement in cows. Zentralbl Veterinarmed A 45: 293-298.

27. Holtenius K, Sternbauer K, Holtenius P (2000) The effect of the plasma glucose level on the abomasal function in dairy cows. J Anim Sci 78 : $1930-1935$.

28. Vlaminck K, Van Meirhaeghe H, Van Den Hende C, Oyaert W, Muylle Y 1985 [Effect of endotoxins on abomasal emptying in cattle]. Dtsch Tierarztl Wochenschr 92: 392-395.

29. Wittek T, Furll M, Constable PD (2004) Prevalence of endotoxemia in healthy postparturient dairy cows and cows with abomasal volvulus or left displaced abomasum. J Vet Intern Med 18: 574-580.

30. Constable PD, Miller GY, Hoffsis GF, Hull BL, Rings DM (1992) Risk factors for abomasal volvulus and left abomasal displacement in cattle. Am J Vet 53: 11841192 .

31. Sattler N, Fecteau G, Helie P, Lapointe JM, Chouinard L, et al. (2000) Etiology, forms, and prognosis of gastrointestinal dysfunction resembling vagal indigestion occurring after surgical correction of right abomasal displacement. Can Vet J 2000. 41: 777-785.

32. Coppock CE (1974) Displaced abomasum in dairy cattle: etiological factors. J Dairy Sci 57: 926-933.

33. Wallace CE (1975) Left abomasal displacement - a retrospective study of 315 cases. Bovine Practitioner 10: 50-58.

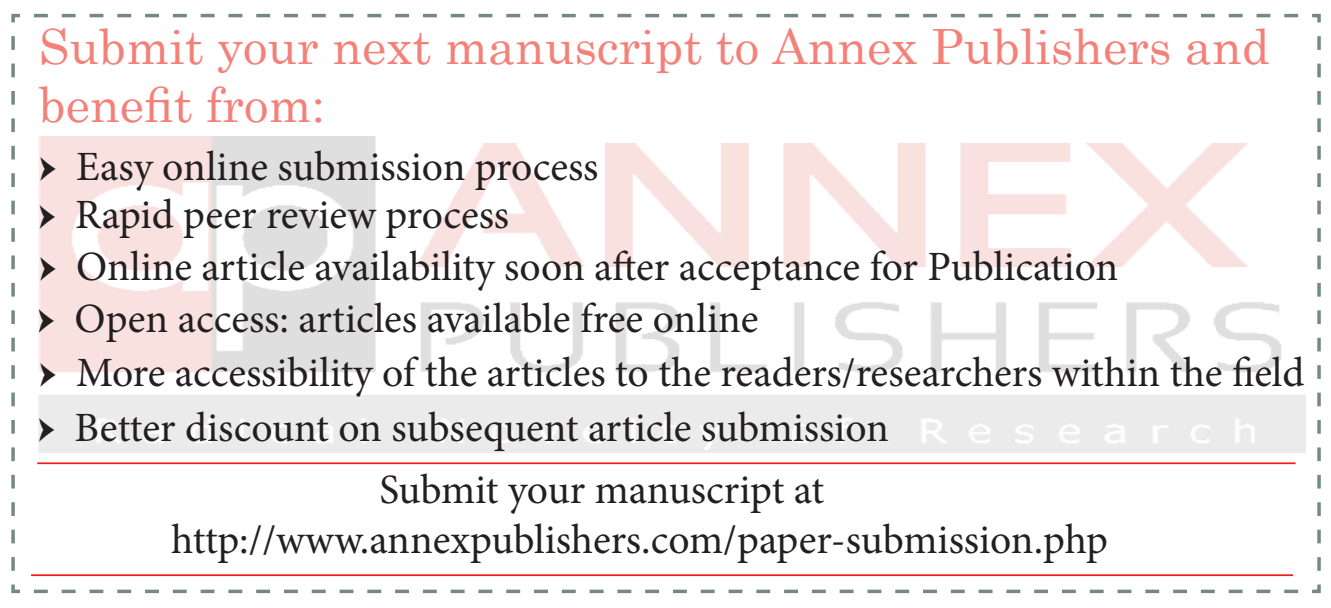

